\title{
Maxillary Artery
}

National Cancer Institute

\section{Source}

National Cancer Institute. Maxillary Artery. NCI Thesaurus. Code C34205.

A terminal branch of the external carotid artery running from the ramus of the jaw to the pterygopalatine fossa with numerous branches supplying the deep structures of the face. 